\title{
Design of machine to remove sharp edges
}

\author{
Peter Michalik ${ }^{1, *}$, Vieroslav Molnár ${ }^{1}$, Jana Fabianová ${ }^{2}$, Michal Petruš ${ }^{1}$, and Norbert Roško $^{3}$ \\ ${ }^{1}$ TU Košice, Faculty of Manufacturing Technologies with seat in Prešov, Bayerova 1, 08001, \\ Slovakia \\ ${ }^{2}$ TU Košice, Faculty of Mining, Ecology, Process Control and Geotechnologies, Košice, Letná 9, \\ 04201, Slovakia \\ ${ }^{3}$ Michalovce, Podjavorinskej 25, 071 01, Slovakia
}

\begin{abstract}
This article deals with the design of machine to remove sharp edges of components for manufacturing. After working with any technology, pressing, casting or machining, sharp edges and dirty surfaces of the finished parts need to be clean and removed by sharp edges. Serial production machines are expensive and are unprofitable for piece and small-lot production. Design materials, electric drives, coupling and damping components selected for the design.
\end{abstract}

\section{Introduction}

Removal of blanks or finished parts Figure 1 may considered an aggressive mechanical finishing process. One way of finishing is by grinding the surface roughness of the material. Grinding is a machining technology for machined parts and materials, in which the material is removed by geometrically undefined cutting wedges of the grinding wheel that separate the work piece surface particles by abrasive grains deposited in the joint, on the tool, or freely.
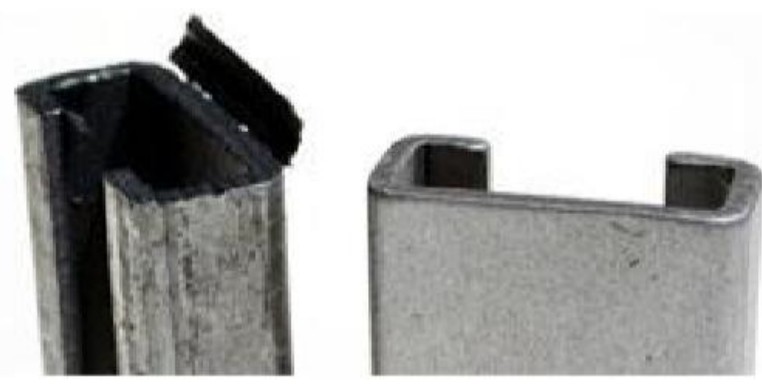

Fig. 1. Remove sharp of the components. Source: [3]

\footnotetext{
* Corresponding author: petermichalik8@gmail.com
} 
Any material that is capable of forming a chisel can be grinded. The components for the transport, manipulator, construction, agricultural and machinery machines are utilized for so-called dehumidifying bodies which are different in size or material. The choice of these bodies depends on the appearance of the work piece [1]. It is not always easy to suggest the correct casting bodies. It is best to send problematic parts, specifying the requirements of a professional company that deals with reconciliation. The company will carry out the necessary tests and will implement the design of the appropriate technology. If the casting bodies have chosen correctly, the results are very good, for example triangular slanting cutters are universally applicable and are particularly suitable for smoothing surfaces, edges, grooves. Special requirements can made with angled and triangular casting bodies. The scraps of the exposed places do not show any deformation during dehumidification. The movement of the parts during unloading in the various dehumidifiers is uniform, without cluttering of the dehumidifiers, or without partial separation of the components $[2$, 4].

\section{Design of individual opinions}

From the point of view of relieving small work piece dimensions, simple work piece separation and high productivity, circular vessel vibrating devices have designed. These maintenance-free vibratory drives are, used, which have a permanent lubricating charge.

\subsection{The first variant}

In the first variant, a machine to remove sharp edges Figure 2 was designed with a circular vessel with a diameter of $\Phi=800 \mathrm{~mm}$, a wall thickness of $8 \mathrm{~mm}$ and a height of $\mathrm{h}=500$ $\mathrm{mm}$ and a total height of the device of $1.3 \mathrm{~m}$.

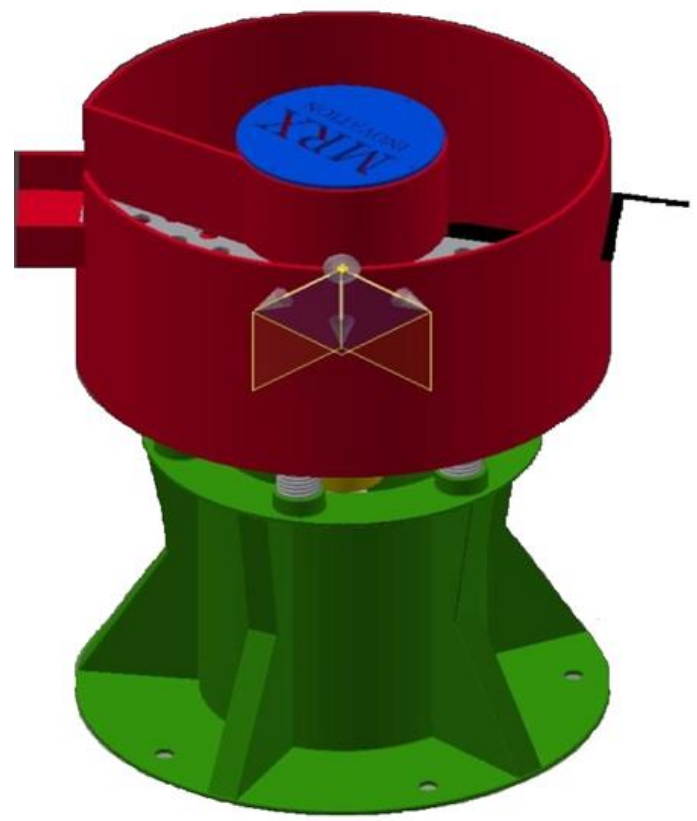

Fig. 2. Assembly the first variant of machine to remove sharp edges. 
A standard flanged electric motor with a shaft weighing weight used for flare. The oscillation of the circular vessel achieved by placing it on six springs fixed to the racks. The stand is made of a longitudinally welded tube with a diameter of $\Phi=400 \mathrm{~mm}$, a height $\mathrm{h}=$ $600 \mathrm{~mm}$ and a wall thickness of $8 \mathrm{~mm}$ and is directly attached at the bottom by a screw connection to the floor of the workshop. The first variant of the device is inappropriate due to the impracticability of separation of the casting bodies from the detached parts. Another reason why we do not choose this device is a conventional electric motor whose bearings not built to cause vibrations on the shaft of the electric motor formed by the weight.

\subsection{The second variant}

In the second alternative, a machine to remove sharp edges Figure 3 designed with a circular vibratory drum. A separating sieve and a separating flap added. The vibration motor MTF 15 / 2000E-SO2 was designed for flare.

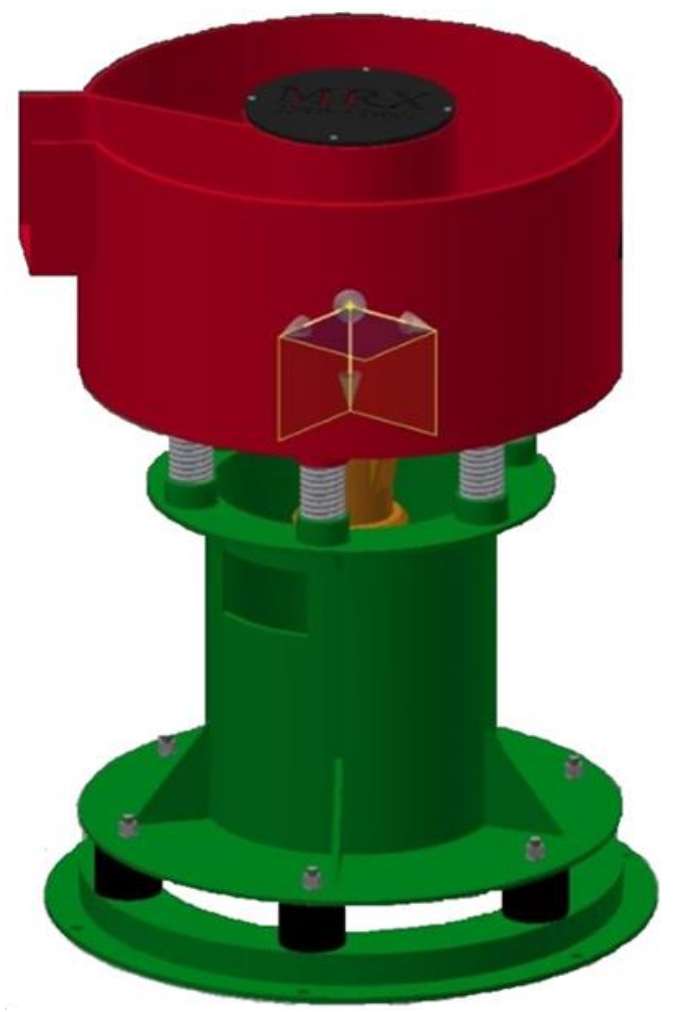

Fig. 3. Assembly the second variant of machine to remove sharp edges.

The dimensions of the drum are smaller than in the first two variants. The height of the drum is $400 \mathrm{~mm}$, the width is $800 \mathrm{~mm}$, the wall thickness is $8 \mathrm{~mm}$ and the drum is tailor made. The rack of the device is less massive due to the smaller weight of the drum and its dimensions are - height $500 \mathrm{~mm}$, top ring width $600 \mathrm{~mm}$, lower ring $800 \mathrm{~mm}$, thickness of longitudinally welded tube $8 \mathrm{~mm}$ and planar components. The drum on the rack fastened using six springs. To reduce the vibrations of the device, $75 \mathrm{~mm}$ thick, $100 \mathrm{~mm}$ thick and M16 threaded fasteners mounted on a separate pedestal on which the drum stand attached. 


\subsection{The third variant}

In the third alternative, a machine to remove sharp edges Figure 4 has been designed which comprises a circular drum mounted on four silencing blocks, which prevent the transmission of undesirable vibrations to the floor of the production hall. Vibration generates an electric vibrator with a power of $0.75 \mathrm{~W}$. On the shaft of the vibration motor, the excitatory has replaced with a $30 \mathrm{~mm}$ offset from the axis of the shaft. The vibrator attached via a console to the spinner drum. The bobbin supported by two pins with a diameter of $40 \mathrm{~mm}$, welded to the structure, welded from steel profiles $60 \times 40 \times 3 \mathrm{~mm}$. The entire dehumidifying machine stands on wheels with brakes for better handling in the production hall.

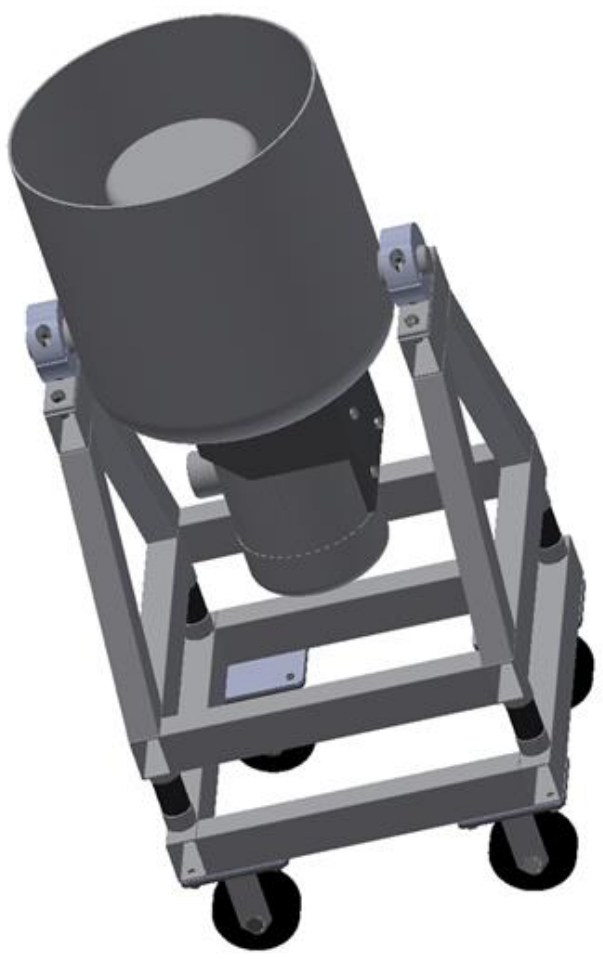

Fig. 4. Assembly the third variant of machine to remove sharp edges.

\section{Selection of variants}

After performing a strength analysis where all variants were loaded with $F=1470$ N. Force $\mathrm{F}$ is the sum of the actual weight of the device and the volume of components considered is 50 liters, the lowest deformations in the third alien were recorded Figure 5. 


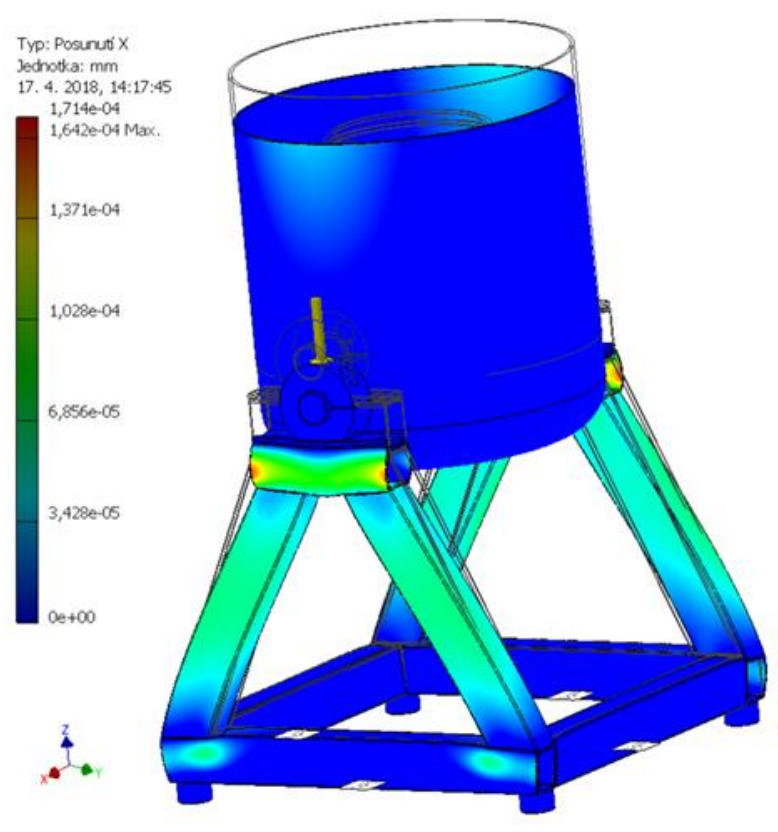

Fig. 5. Stress analyse in axis $X$.

\subsection{Construction of selection variant}

The construction of the machine to remove sharp edges consists of a base frame Figure 6 , a supporting frame Figure 7 and a drum Figure 8. These three parts made as enclosures from closed steel profiles $60 \times 40 \times 3 \mathrm{~mm}$.

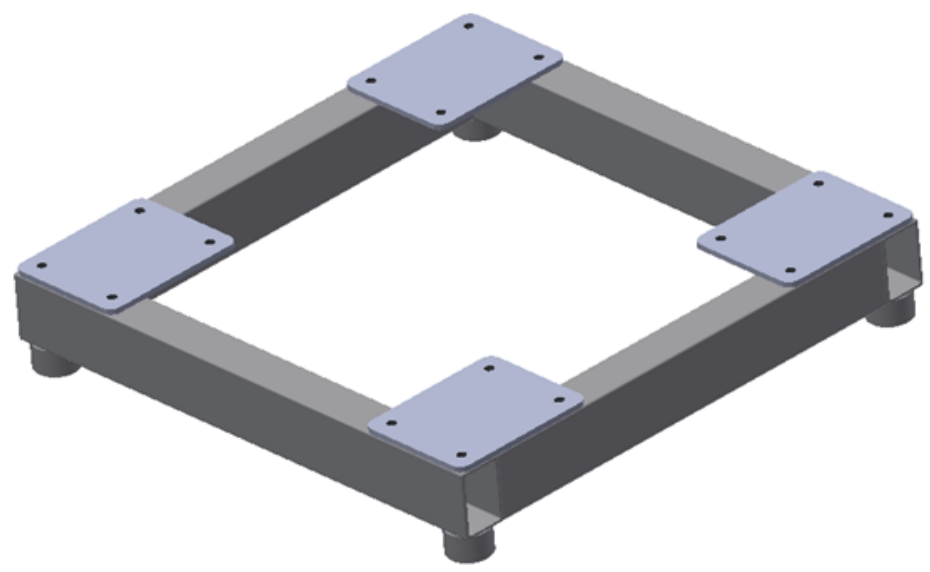

Fig. 6. Assembly of basic frame. 
At the bottom of the structure, the casing is fitted with vibrating rubber. On the other part of the structure are the plates on which the wheels screwed.

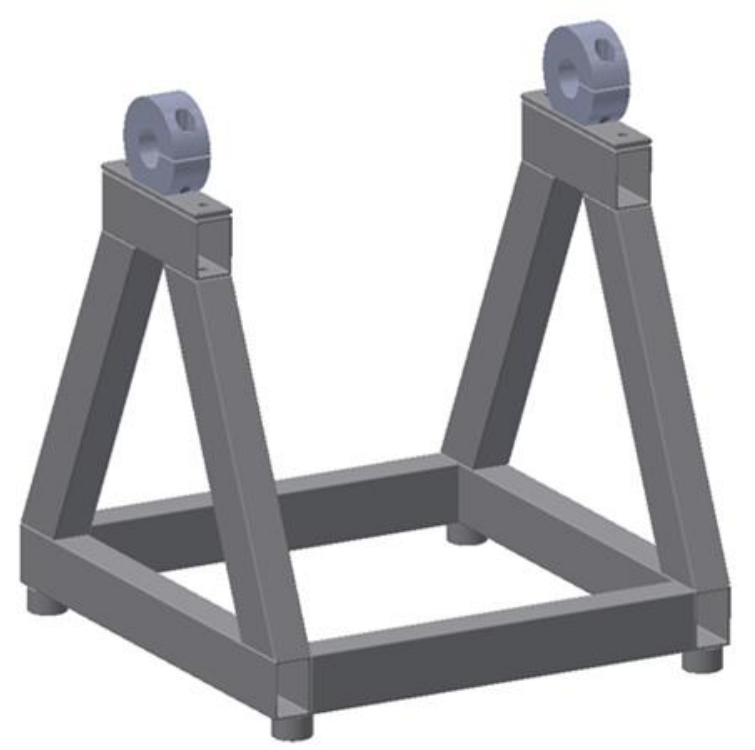

Fig. 7. Assembly of carrier frame.

In addition, two of the two opposing cartridges in which the pins on which the drum will pulled will be stored. During dehumidification, the drum secured with screws in the housings to prevent the drum from tipping before the cycle is completed.

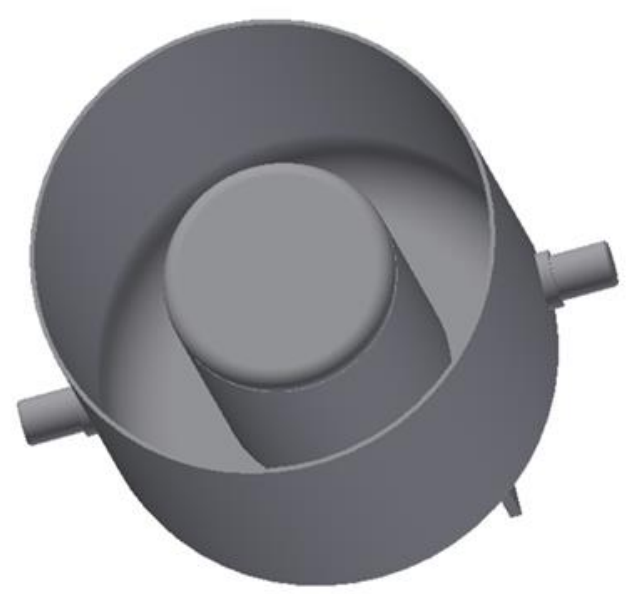

Fig. 8. Assembly of soap bubble. 


\section{Conclusion}

The design of the design of the chosen alternative of the dehumidifying machine and its production from the available domestic materials of both profiles and semi-finished products will save time and will, in particular reduce the cost of machining the surface of several components at once. After the models developed, the alternatives analysed and a suitable alternative of the dehumidifying machine taken into account, taking into account the material possibilities for drawing up the drawing documentation. After approval of the financial requirements, the implementation of the design of the dehumidifying machine, which should replace the industrially produced dehumidifiers, respectively, will carried out milling machines.

This work is a part of research project VEGA 1/0045/18.

\section{References}

1. Used and Second Hand Rosler Machines [online], Available from: https://cz.rosler.com/cz-cs/produkty/omilaci-stroje/kruhove-vibratory (2004)

2. Q Surface pretreatment, [online]. Available from: http://www.sjf.tuke.sk/inmf/NW/mpp/omie\%C4\%BEanie.html, (2004)

3. A Comparison: Dehumidification Versus Heat in Construction Drying Applications, Available from: http://www.awci.org/media-archives/construction-dimensions/1017-acomparison-dehumidification-versus-heat-in-construction-drying-applications, (2018)

4. Construction of dehumidifier / analysis report, [online], Available from: https://www.slideshare.net/sajaltiwari05/construction-of-dehumidifier-analysis-report, (2004) 